\title{
RECENT ADVANCES IN PEDIATRICS
}

\author{
WARREN E. WHEELER, M.D., \\ Department of Pediatrics, The Ohio State University
}

The time allotted could be spent entirely in merely cataloguing the many recent advances in Pediatrics. Instead of this, I would prefer to discuss in some detail two of the concepts which have grown to prominence recently which appear to be of fundamental importance.

\section{CONGENITAL ANOMALIES FOLLOWING GERMAN MEASLES IN THE PREGNANT MOTHER}

Until the past few years it has been generally accepted that congenital malformations result from defects in germ plasm existent prior to conception. A very significant advance in thinking concerning the etiology and prevention of such anomalies has followed the demonstration that maternal infection may also play a part in their origin. Following an epidemic of German Measles in Australia, Gregg (1) noted what seemed to him to be a veritable epidemic of babies born with eye and heart anomalies. Further study revealed that most of these particular babies had been born of mothers who had had rubella during their pregnancy. Swan (2), also in Australia, soon corroborated these observations and extended them to include pathologic reports of three such infants who died of intercurrent infections. At least five American authors have also found similar cases in their experience (3). To the present, these workers have reported 145 instances of various congenital anomalies in mothers with a history of rubella during pregnancy. In 77 of these, the anomalies were multiple. Mental deficiency was seen in 88 cases, cataracts in 112 cases, heart malformations in 83 cases, microphthalmos in 13 cases, and deaf mutism in 12 cases. It seems inconceivable that such a number of malformations should be brought to light in the few mothers that wait until pregnant to develop this childhood disease.

It is obvious that attention has been called to this relation because of the malformations rather than the maternal rubella. However, it is difficult to collect accurate statistics on the total number of mothers who have rubella during pregnancy and subsequently compare their offspring with a control series as to the incidence of anomalies. There might be considerable doubt concerning the validity of the above relationship if it were not for another observation too unique to be due to coincidence. With the exception of four cases, all the 145 mothers had their rubella before the fourth month of pregnancy. Swan reported observations on 49 cases of rubella in all stages of pregnancy of which 25 occurred before the third month. Every one of these infants was malformed. Four out of eight infants whose mothers had their disease in the third month were malformed, while beyond the third month, only two out of sixteen showed defects. This fact has led to speculation that the fetal infection which is assumed to occur must affect the fetus during a stage of critical development of the eye and heart structures for an anomaly to result.

These results have stimulated several investigators to explore the possibility of other maternal infectious diseases leaving deformed offsprings in their wake. This search has so far been rather fruitless since only two cases have been found in which the mother had mumps, and two in which she had influenza. Apparently German Measles is not as innocuous as was once thought. These observations and similar ones of his own have led Erickson to suggest mandatory abortion of any mother acquiring the disease in the first trimester of pregnancy.

CYSTIC FIBROSIS OF THE PANCREAS

Anderson (4), and Blackfan and May (5) independently in 1938 described a syndrome in infants resembling celiac disease in some respects which has come to 
be known as cystic fibrosis of the pancreas. This is not a particularly rare disease, for we see four to six cases a year at Children's Hospital. Attention was directed to the condition by the observation that some children with celiac syndrome eventually recovered, while others suffered repeated and severe pulmonary infections which were invariably fatal. According to the concept developed by Farber, the condition is an hereditary one. Sometimes at birth and other times during the first year, the secretion of the pancreas becomes so thick and viscid as to effectively plug the secretory ducts and stop the flow of pancreatic juice. This deprives the bowel of pancreatic enzymes and leads to a fatty diarrhea. As the result of the plugging of the ducts, the acini become grossly dilated and cystic, and the pancreas undergoes fibrosis. This picture of pancreatic involvement is striking and constant. However, many other glands in the body may also undergo the same alteration in secretory power. The bronchial mucus glands are often involved, resulting in the secretion of a substance so thick and tenacious that it cannot be effectively removed from the bronchial tree. Infection with low grade pathogens from the pharynx (Staphylococcus aureus usually) then takes place following an upper respiratory infection. The pneumonia is characterized by marked emphysema from the air trapped behind the sticky plugs of mucus. Clinically, these patients are usually thought to have whooping cough at first, so violent are their attempts to clear their air passages. The salivary glands, lachrymal glands, Brunner's glands, and even the liver have in some cases been the site of the same unphysiologically thickened secretion.

The pancreatic deficiency causes a loss of excess fat and protein in the stool, so that these children may be quite malnourished though possessed of an exceptionally good appetite. Even more important is the aspect of pulmonary infection which, once it becomes established, is with rare exceptions fatal in the end.

The diagnosis is complicated by the insidiousness of the onset. In most of the cases, the true nature of the condition has been first found at autopsy. Recently, however, it has been recognized during life by suspecting the condition in any infant with so-called whooping cough, or chronic pneumonia, or repeated bronchitis whether or not the child also shows evidence of steatorrhea. Thus, clinically, although the disease is still called cystic fibrosis of the pancreas, most diagnoses during life are made by attention to the pulmonary symptoms.

The true nature of the condition is established by demonstrating the absence of the enzyme trypsin in the pancreatic juice. This is accomplished by sampling the contents of the duodenum in the fasting state by means of a Levine tube. Dilutions of the duodenal juice are then allowed to act on gelatine. If the gelatine is not liquified, it is taken as evidence of an absence of trypsin. The procedure is more difficult than it sounds since it is a long and arduous one, especially in a child who is dyspneic from his pulmonary involvement. Any contamination of the duodenal juice with stomach acid may invalidate the test, and sometimes it is practically impossible to enter the duodenum with the Levine tube.

Recently, West and Wilson have proposed an equally logical test based on the observation that these children cannot break down proteins sufficiently into their ultimate amino acid components. A test meal of casein or gelatine is given after a fasting determination of the blood amino acid content. Thereafter, in the manner of a glucose tolerance test, serial amino acid "levels" are taken. Normally the fasting value is close to $1 \mathrm{mg}$. \%. In the normal infant this rises to 4 or 6 mg. \% after a casein meal. In cystic fibrosis of the pancreas, there is no significent rise.

\section{BIBLIOGRAPHY}

1. Gregg, N. M. Tr. Ophth. Soc. Australia, 3, 35, 1941

2. Swan, C., Tostevin, A. L., Mayo, H., and Black, G. H. B. M. Journ. Australia, 2, 201, 1943 (Sept. 11), ibid, 1, 409, 1944 (May 6).

3. Conte, W. R., McCammon, C. S., and Christie, Amos. Am. J. Dis. Child., 70, 301, 1945 (Dec.).

4. Anderson, D. H. Am. J. Dis. Child., 56, 344, 1938 (Aug.).

5. Blackfan, K. D., and May, C. D. Journ. Ped., 13, 627, 1938 (Nov.). 